\title{
Radiographic diagnosis and surgical management for successful outcomes for osteochondrosis in Japanese Black calves
}

\author{
Mrunmayi Vishwanath NAIK ${ }^{1)}$, Yumi KIRINO'1), Ryoko UEMURA ${ }^{2)}$, Sueun KIM"1), \\ Yoshiyuki INOUE ${ }^{1)}$ and Yuichi HIDAKA ${ }^{1) *}$ \\ 1)Laboratory of Veterinary Surgery, Department of Veterinary Science, University of Miyazaki, 1-1 Gakuen \\ Kibana-dai Nishi, Miyazaki 889-2192, Japan \\ 2)Laboratory of Animal Health, Department of Veterinary Science, University of Miyazaki, 1-1 Gakuen \\ Kibana-dai Nishi, Miyazaki 889-2192, Japan
}

J. Vet. Med. Sci.

83(1): 151-157, 2021

doi: 10.1292/jvms.20-0310

Received: 24 May 2020

Accepted: 17 November 2020

Advanced Epub:

28 December 2020

\begin{abstract}
Osteochondrosis (OC) is not well recognized in cattle. Japanese Black (JB) cattle are valued for their beef and studies regarding OC are scarce. Hence, the aim of this study was to retrospectively discuss clinical and radiographical findings, diagnosis and treatment options for OC in JB cattle for successful outcomes. Medical records of 11 calves affected with OC were reviewed, retrospectively. Clinical and radiographic findings, treatment and outcomes and postmortem examination findings were analyzed. All calves had lameness. Stifle (4/14) and tarsal (4/14) were the most affected joints. Subchondral bone lucencies were observed in all joints (14/14) and accompanied with sclerosis (10/14). Radiographic grading was performed in calves. Calves were treated surgically $(8 / 11)$ or conservatively $(1 / 11)$. Surgically treated calves were auctioned (5/8). Postmortem examination was performed (2/11). Gross findings revealed ulcerative lesion at articular surface. Histopathologically, cartilage layer was defected at lesion. Inflammation (2/2) and granulation tissue (1/2) was also observed. In conclusion, OC in JB cattle can be diagnosed on the basis of radiography with history and clinical signs in clinical setting. Surgery should be performed in mild cases for successful outcomes. A modified radiographic grading criteria for clinical cases may hold potential in evaluating prognosis and outcomes.

KEY WORDS: Japanese Black calf, osteochondrosis, radiographic diagnosis, surgical management
\end{abstract}

Osteochondrosis $(\mathrm{OC})$ is a developmental disorder of growing animals affecting the normal endochondral ossification process $[2,11]$. It is a well-documented condition in horses and pigs but is rarely recognized in cattle [2, 11]. Numerous risk factors are attributed such as genetics, trauma and diet $[2,3,11]$ however, the etiology and pathogenesis is still debatable. In cattle, commonly affected joints are the stifle, tarsus and atlanto-occipital $[6,8,12,14]$. OC in cattle has also been reported in the shoulder and carpal joints $[16,18]$. This disease is slow in progression and early clinical signs can be easily missed.

There is a dearth of studies describing clinical and radiographic findings as well as treatment because many cases in cattle are asymptomatic and accidentally observed during postmortem examination. With the slow progression, variable degree of lameness and joint effusion which is non-specific and unclear radiographic evidence of early stages of OC, it poses a challenge to the veterinarian to understand the disease and initiate treatment. In addition, it is difficult for the field veterinarians to distinguish between OC and Mycoplasma origin joint swelling on farms in cattle without skin wound and synovial fluid could not be aspirated to rule out Mycoplasma infection. In such cases, tentative diagnosis of joint swelling is suspected to be Mycoplasma bovis in origin due to the veterinarian's prejudice and past experiences.

The Japanese Black (JB) is a popular cattle breed raised in Japan for its prime beef and hence is highly valued. Most research involving JB cattle is either related with nutrition, reproduction and pneumonia but much less about bone and joint diseases. There is a paucity of studies regarding orthopedics including OC in JB cattle despite the prevalence of the condition which causes economic losses.

Over the past few years, authors encountered 11 cases of OC in JB calves. To the author's knowledge, clinical and radiographical findings in JB calves have not been described except a case report [16]. The aim of this study was to retrospectively discuss clinical and radiographical findings, diagnosis and treatment options of chronic OC in JB cattle for successful outcomes. 


\section{MATERIALS AND METHODS}

\section{Case selection}

Clinical records of all JB calves affected with joint inflammation which were referred to the Veterinary Teaching Hospital, University of Miyazaki between April, 2013 and March, 2019 were reviewed. For inclusion, calves had to have radiographic evidence of OC. Calves with luxation, fractures and septic arthritis including bacterial and Mycoplasma origin were excluded.

\section{Medical records}

Findings of physical and lameness examination, radiography, synovial fluid (SF) analysis, treatment and outcomes were obtained from their medical records and reviewed, retrospectively. Outcomes were determined through referred veterinarians or owners. Lameness examination score was based on a scale of 0 (no lameness) to 4 (non-ambulatory) as previously described in cattle [5]. Contralateral limbs were evaluated for limb deformities secondary to chronic lameness.

\section{Radiography}

Radiography was conducted using a portable machine. Radiographical images were obtained in all calves in two directions (cranio-caudal and lateral) in diseased and contralateral healthy joint. Radiographs were assessed for subchondral bone cyst-like lesions, subchondral bone defects and bony fragmentation. Sclerosis was defined as increased bone density surrounding the cyst like lesion. Radiographs were also checked for evidence of degenerative joint disease. Grading of OC lesions was based on a previous report in horse [1] and is shown in Table 1.

\section{Treatment and outcomes}

Treatment included either surgery or conservative management.

a) Surgery (arthrotomy): surgical treatment was chosen for unresolved cases. The procedure was similar for all calves and is described in brief. The calf was sedated with an intravenous injection of $2 \%$ xylazine. An endotracheal tube was inserted, and anesthesia was maintained with isoflurane in oxygen. The calf was positioned in either left/right lateral recumbency or dorsal recumbency depending on the affected joint. The joint was prepared aseptically for surgery. Incision site (lateral $/ \mathrm{medial} / \mathrm{cranial}$ approach) was determined by the location of lesion confirmed via radiography. After incision, blunt dissection of connective tissues was performed, followed by joint space confirmation. Next, fibrin clots were removed followed by joint lavage using warm normal saline. Then, debridement of cartilage and bone lesions were performed. The incision was closed in routine manner. Post-operatively the surgical wound was covered with bandages and changed daily. We checked the wound's condition and color and odor of fluid from the wound. Antibiotics (2-19 days) and analgesic drugs (2-4 days) were administered to all calves. Rehabilitation was carried out for all calves and included slow walking (5-10 min) daily. We evaluated weight bearing ability and gait during rehabilitation. Post-operatively, calves were kept in hospital between 2 days to 19 days. Only one calf was discharged after surgery on the same day.

b) Conservative management: one case (Case No. 4) received conservative treatment in the field. Treatment included stall rest, rehabilitation, and intra-articular (IA) medication. IA medication consisted of an injection of dexamethasone (2.5 ml) for a period of eight days. In addition, an antibiotic was administered for the same period through systemic route to the animal to prevent iatrogenic infection. Prior to IA injection, the joint was prepared aseptically. Post IA injection, the animal was given stall rest, rehabilitation at intervals and observed for improvement of lameness and weight bearing on the affected joint.

\section{Outcomes}

The outcomes were evaluated with clinical course observation and judged based on result of cattle auction, fattening or slaughter.

\section{Postmortem examination}

Pathology was performed in two cases. In brief, diseased joint samples were trimmed and fixed with $10 \%$ neutral buffered formalin solution. After fixation, IA lesions were observed, grossly. The tissues were decalcified by immersing in $10 \%$ formic acid. The joint tissues were further trimmed and embedded in paraffin by routine procedure. The tissue blocks were sectioned and specimens were stained with hematoxylin and eosin and alcian blue for light microscopic observation.

Table 1. Radiographic grading of osteochondrosis lesions

\begin{tabular}{cllll}
\hline Grade & Contour & \multicolumn{1}{c}{ Bone texture } & \multicolumn{1}{c}{ Subchondral bone } \\
\hline 0 & Normal & Rounded & With diffuse density & Absent \\
1 & Minimal & Smoothly flattened & With obscure lucency & Absent \\
2 & Mild & Irregularly flattened & With obvious lucency, limited and poorly defined border & Absent \\
3 & Moderate & Small, rounded, or irregular concavity & With obvious, well-defined local lucency & Small fragment(s) \\
4 & Severe & Large, rounded or irregular concavity & With obvious, well-defined extensive lucency & Large fragment(s) \\
\hline
\end{tabular}

Cited from Baccarin et al [1]. 


\section{RESULTS}

\section{Clinical examination}

Eleven pure bred JB calves were included in this study and comprised of seven males and four female animals and summarized in Table 2. The mean age of diagnosis at presentation at the University Hospital was 4.6 months (range: one to nine months). Routine physical and blood examination were within acceptable range. Lameness was characterized by reluctance to walk and bear weight on the affected limb. Nine calves had lameness scores entered in their medical records. Six calves had grade 1 lameness and three calves had grade 2 lameness. Four stifles and four tarsi were the most affected joints followed by three carpi, two fetlocks and one elbow. In one calf, stifle joint was affected bilaterally. In two calves, one joint was affected on forelimb and hindlimb simultaneously (Fig. 1). In one calf (tarsal, carpal joints) and other calf (tarsal, fetlock joints) were affected, respectively. A dropped fetlock was observed on contralateral joint in one calf.

\section{Radiographic examination}

Radiographic lesions were detected in all 14 affected joints and summarized in Table 3. Subchondral bone lucencies were observed in all joints (Fig. 2) and accompanied with sclerosis in 10 joints (Fig. 3). Multiple cyst lucencies were observed in three joints. Abnormalities involving the opposite articulating surface were observed in four joints. Radiographic grading was performed in 12 joints. Five joints had grade 1, three joints had grade 2, one joint had grade 3 and three joints had grade 4 radiographic grading, respectively (Table 3). Three joints were classified as grade 1 because of smooth flattening and obscure lucency. Two joints were classified as grade 1 despite obvious lucency, because of smooth flattening. Two joints were classified as grade 2 in spite of obvious lucency because of irregular flattening and no fragment. One joint was classified as grade 3 because of welldefined extensive lucency despite difficulty in evaluating bone texture because of severity of lesions (irregular flattening or small concavity). Three joints were classified as grade 4 because of well-defined extensive lucency and large concavity despite no

Table 2. Clinical characteristics, radiography, and treatment outcomes of Japanese Black calves in this study

\begin{tabular}{|c|c|c|c|c|c|c|c|c|c|}
\hline $\begin{array}{l}\text { Case } \\
\text { No. }\end{array}$ & $\mathrm{Age}^{\mathrm{a})}$ & Sex & $\begin{array}{l}\mathrm{BW}^{\mathrm{b})} \\
(\mathrm{kg})\end{array}$ & $\begin{array}{l}\text { Affected joint } \\
(\mathrm{L} / \mathrm{R})\end{array}$ & $\begin{array}{l}\text { Lameness } \\
\text { score }^{\mathrm{c})}\end{array}$ & $\begin{array}{c}\text { Radiographic } \\
\text { diagnosis (OC, DJD) }\end{array}$ & Treatment & Clinical course & Outcomes \\
\hline 1. & 3 & Female & 100 & Carpal: $\mathrm{R}$ & -d) & $\mathrm{OC}+\mathrm{DJD}$ & Surgery & Improved & Auctioned \\
\hline 2. & 2 & Female & 46 & Stifle: L & 1 & OC & Surgery & Improved & Auctioned \\
\hline 3. & 4 & Male & 132 & Tarsal: L & 1 & $\mathrm{OC}+\mathrm{DJD}$ & Surgery & Improved & Auctioned \\
\hline 4. & 5 & Male & 95 & Tarsal: L & 1 & $\mathrm{OC}+\mathrm{DJD}$ & Conservative & Guarded & Fattening \\
\hline 5. & 4 & Male & 128 & Elbow: R & 2 & $\mathrm{OC}+\mathrm{DJD}$ & -f) & - & - \\
\hline 6. & 1 & Male & 40 & Stifle: R & 1 & OC & Surgery & Improved & Auctioned \\
\hline 7. & 9 & Male & 230 & Fetlock: L & 1 & $\mathrm{OC}+\mathrm{DJD}$ & Surgery & Guarded & Fattening \\
\hline 8. & 7 & Male & 239 & Carpal: R & 1 & $\mathrm{OC}+\mathrm{DJD}$ & Surgery & Improved & Auctioned \\
\hline 9. & 2 & Female & 40 & Stifle: $\mathrm{R}+\mathrm{L}$ & d) & Bilateral OC & Surgery & Deteriorated & Slaughter \\
\hline 10. & 7 & Female & 187 & $\begin{array}{l}\text { Tarsal: L } \\
\text { Fetlock: L }\end{array}$ & 2 & $\begin{array}{l}\mathrm{OC} \\
\mathrm{OC}\end{array}$ & Surgery & Deteriorated & Slaughter \\
\hline 11. & 7 & Male & 133 & $\begin{array}{l}\text { Tarsal: R } \\
\text { Carpal: L }\end{array}$ & 2 & $\begin{array}{l}\text { OC+ DJD } \\
\text { OC }\end{array}$ & -f) & - & - \\
\hline
\end{tabular}

a) Age at presentation to University Hospital in months, b) body weight, c) lameness score as described in manuscript, d) lameness score not recorded in medical records, e) OC: osteochondrosis, DJD: degenerative joint disease, f) treatment not performed.

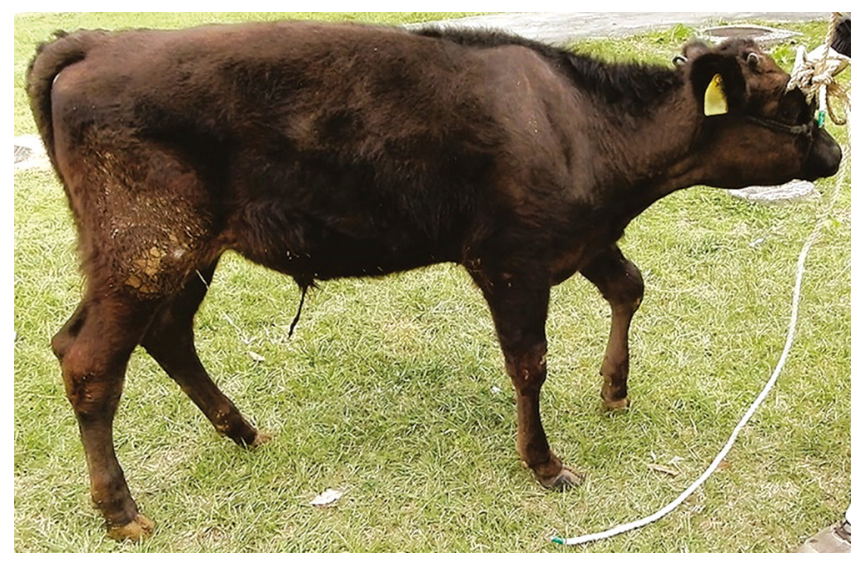

Fig. 1. A calf affected with right tarsal joint and left carpal joint. 
Table 3. Radiographic findings in this study

\begin{tabular}{|c|c|c|c|c|c|c|c|}
\hline \multirow{2}{*}{ Joint } & \multirow{2}{*}{ Site } & \multirow{2}{*}{$\begin{array}{l}\text { Subchondral bone } \\
\text { cyst-like lesion }\end{array}$} & \multicolumn{4}{|c|}{ Grading ${ }^{a)}$} & \multirow{2}{*}{$\mathrm{DJD}^{\mathrm{b})}$} \\
\hline & & & 1 & 2 & 3 & 4 & \\
\hline \multirow[t]{3}{*}{ Stifle $(n=4)$} & Lateral condyle $(\mathrm{n}=2)$ & 2 & 1 & 1 & 0 & 0 & 0 \\
\hline & Medial condyle $(n=1)$ & 1 & 0 & 0 & 0 & 1 & 0 \\
\hline & Tibial plateau $(\mathrm{n}=1)$ & 1 & 1 & 0 & 0 & 0 & 0 \\
\hline \multirow[t]{2}{*}{ Tarsal $(n=4)$} & Tibial tarsal bone $(\mathrm{n}=3)^{\mathrm{c})}$ & 3 & 1 & 1 & 0 & 0 & 2 \\
\hline & Distal row of tarsal bones $(\mathrm{n}=1)$ & 1 & 0 & 0 & 1 & 0 & 1 \\
\hline \multirow[t]{3}{*}{ Carpal $(n=3)$} & Proximal row of carpal bones $(n=1)$ & 1 & 0 & 0 & 0 & 1 & 1 \\
\hline & Intermediate carpal $(\mathrm{n}=1)$ & 1 & 1 & 0 & 0 & 0 & 0 \\
\hline & Proximal extremity of metacarpal $(n=1)$ & 1 & 0 & 1 & 0 & 0 & 1 \\
\hline Fetlock $(\mathrm{n}=2)$ & Distal extremity of metacarpal $\left.(\mathrm{n}=2)^{\mathrm{c}}\right)$ & 2 & 1 & 0 & 0 & 0 & 1 \\
\hline Elbow $(n=1)$ & Proximal extremity of radius and ulna $(\mathrm{n}=1)$ & 1 & 0 & 0 & 0 & 1 & 1 \\
\hline
\end{tabular}

a) Radiographic grading as described in manuscript, b) coexisting radiographic evidence of degenerative joint disease (DJD), c) radiographic grading was not performed in one joint.

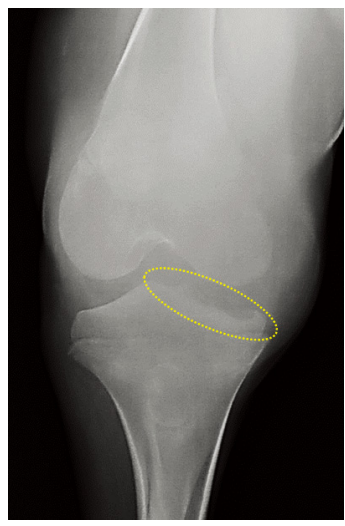

Fig. 2. Radiographic image showing subchondral bone lucency (yellow oval) in stifle joint. Cranio-caudal view.

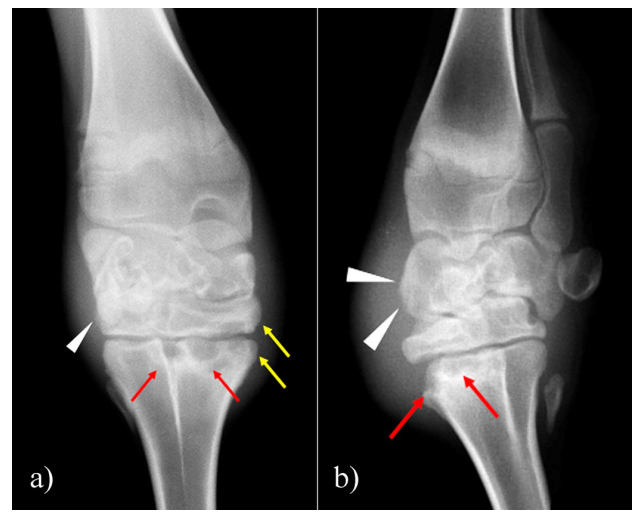

Fig. 3. Radiographic image showing subchondral bone lucency surrounded by sclerosis (red arrows), multiple obscure lucency (yellow arrows) and mild osteoproliferative change (white arrowheads) in carpal joint. The opposite articular surface is also affected. a) Cranio-caudal view, b) lateral view.

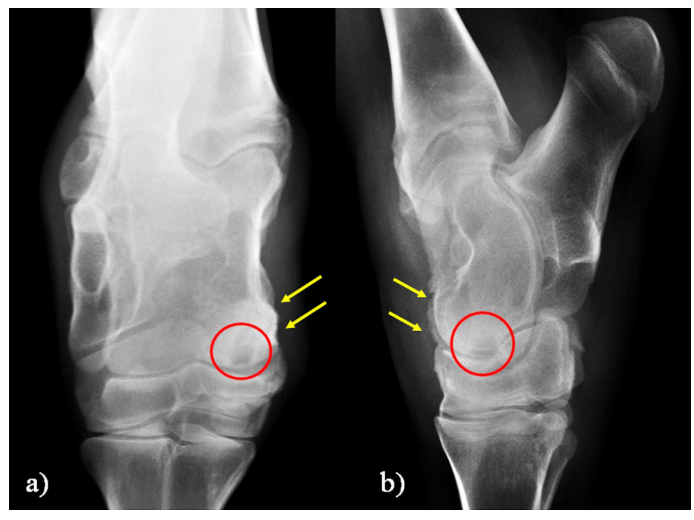

Fig. 4. Radiographic image showing subchondral bone lucency (red circle) accompanied with mild periarticular osteoproliferation (yellow arrows) in tarsal joint. a) Cranio-caudal view, b) lateral view.

fragment. Grading could not be performed in two joints. Grading parameter also includes the texture of bone of the corresponding subchondral bone. In one joint, lesion was observed in the middle aspect of tibial tarsal bone. In second joint, though the lesion was observed in the distal part of metacarpal bone, the articulating bone was not involved. Seven joints also had evidence of degenerative joint disease along with OC (Fig. 4).

\section{Arthrocentesis}

Arthrocentesis was successful in four joints. One sample was contaminated by blood. The mean total protein was $3.0 \mathrm{~g} / \mathrm{dl}$ (range: 2.0-5.0 g/dl; reference range: $1.0-4.0 \mathrm{~g} / \mathrm{dl}$ ) [17] and mean cell count was $2,966 \mathrm{cells} / \mu \mathrm{l}$ (range: $1,800-5,000$ cells/ $\mu \mathrm{l} ;$ reference range: $234-2,500$ cells/ $\mu 1$ ) [17]. Direct smears were analyzed for differential leukocyte count and bacteria. Direct smears revealed non-septic inflammatory response and no bacteria.

\section{Treatment outcomes}

Eight calves underwent surgery (arthrotomy), and one calf was treated conservatively. Two calves were directly sent for postmortem examination because owners declined further treatment at the time of diagnosis. Among eight calves undergoing surgery, five calves were auctioned finally, while one calf which did not qualify for the auction standard was sent for fattening and two calves were sent to slaughterhouse, respectively. One calf treated conservatively was sent for fattening.

\section{Postmortem examination}

Gross findings in two calves were very similar and both cases had ulcerative lesion at articular surface covered by a fibrin plug. 


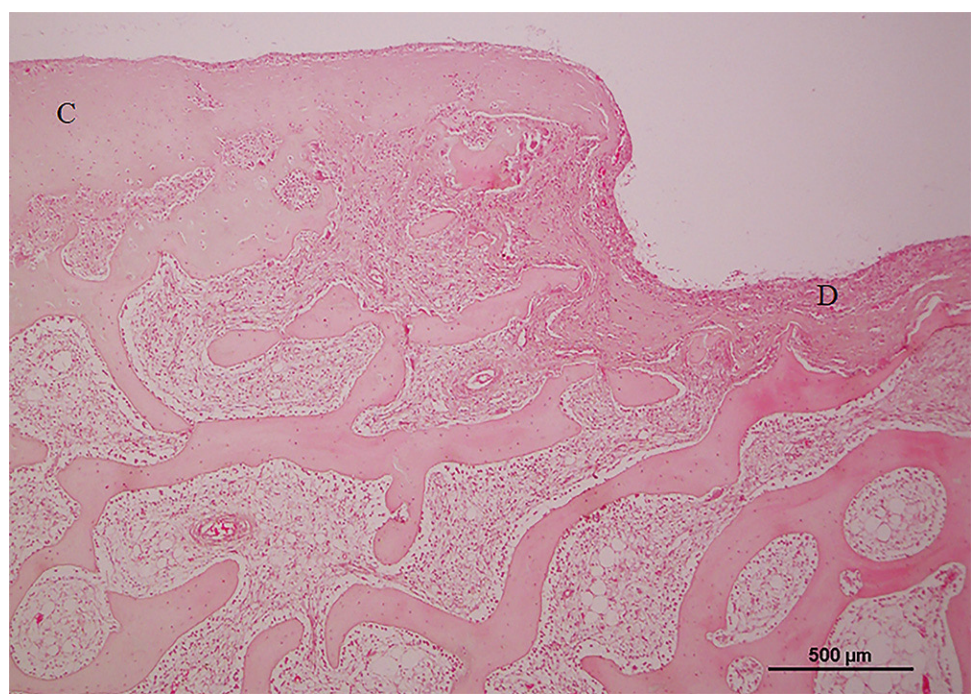

Fig. 5. Histopathological finding showing defect of chondral layer (D) at ulcer lesion. C: chondral layer (hematoxylin and eosin stain).

Histopathologically, in both cases, cartilage layer was defected at the ulcerative lesion (Fig. 5) which covered the connective tissue lined by suspected synovial cells. Inflammatory response, chiefly mononuclear cells, were infiltrated in connective tissue and bone marrow around the lesion. In the layer just below the ulcerative lesion and around inflammatory lesion, necrotic and fragmented trabecular bones were scattered, which were accompanied by numerous activated osteoclasts. In cartilage around the lesion, hyalinization was observed in chondral layer. Granulation tissue was present around the inflammatory lesion in one calf.

\section{DISCUSSION}

This retrospective study describes the findings of clinical signs, radiography and treatment outcomes of OC in JB calves. Diagnosis of OC in this study was based on history, clinical signs, radiographic examination previously described in other cattle OC reports $[4,6,8,11,12,14,21]$ except JB cattle. In this study, calves showed insidious onset of lameness, lack of external lesions and typical radiographic signs in affected joints, which helped to eliminate other common joint diseases such as septic arthritis of bacterial and Mycoplasma origin.

Lesions observed on radiographs were similar in all calves. Typical changes seen were subchondral bone lucency and sclerosis. Radiographs in basic directions could identify lesions in all calves. Lateral and cranio-caudal radiographic projection were enough to identify subchondral bone lucency even in anatomically complex tarsal joint. In case of stifle and carpal joints, cranio-caudal view was superior whereas in elbow it was the lateral view in this study. These observations regarding radiographic projections can be applied in field conditions where resources are minimal. But consideration must be given to the age of the animal because with increase in bone density and muscle mass, these views may not suffice.

Concurrent secondary degenerative joint disease was observed in seven joints and this study could not corroborate the link between OC and degenerative joint disease. However, previous reports in cattle have indicated a strong developmental relationship between these two diseases $[2,13,22]$. Radiographic grading findings suggested that a grade 1 /grade 3 case and a grade 4 case with coexisting degenerative joint disease were sent to slaughter in comparison to grade 1 case, grade 2 cases and a grade 4 case with degenerative joint disease. However, even without degenerative joint disease, a grade 1 /grade 4 bilateral OC case was sent to slaughter. These results indicate that grade 3 and grade 4 cases had a guarded to poor prognosis especially if more than one joint is affected. In this study, grading was based on a previous report of horse describing development of OC lesions in predilection sites only. However, we applied that grading system to all the affected joints in this study. In addition, we must take into consideration the anatomical differences of different joints and bones and bone sizes, to clearly define concavity size to apply grading criteria in affected joints. A modified grading system adapted to suit clinical cases must be given consideration in future to utilize radiographic grading as a potential marker for prognosis and outcomes.

In present study, the calves displayed a variable degree of joint effusion and long-standing lameness. Author's speculate that the time elapsed between disease initiation to the development of clinical signs was the primary reason. The chronic lameness could have also been caused due to the difficulty in detecting initial lesions on radiographs. Computed tomography (CT) is not routinely utilized in cattle due to economic constraints. Although it is uncommon to diagnose OC by CT so far, it can be a potential tool to visualize the existence and the degree of OC lesion in calves with unknown lameness according to a previous report showing its usefulness in degenerative joint disease in female calves [13]. The study suggested that the use of CT gave better understanding of changes in the bones. Hence, CT would be useful when lesions cannot be comprehended on plain radiographs. Unknown origin lameness needs to be addressed quickly because chronicity usually leads to contralateral limb deformities [5]. 
The most affected joints in this study were the stifle and tarsus, which is very consistent with other cattle studies $[4,6,12,14$, 21]. A joint each on forelimb and hindlimb were affected simultaneously in two calves, which is an interesting finding in this study because OC commonly presents itself as a bilateral disorder of the same joint $[4,12]$. In this study, calf affected with both stifles showed effusion and radiographic lesions bilaterally. However, in a clinical OC paper, authors reported less than 40 per cent of cases displayed clinical signs of bilateral OC but 88 per cent had radiographic evidence of OC [21]. The findings emphasize the need for bilateral radiography in future cases because animals maybe asymptomatic even if there is radiographic evidence of OC.

JB calves in this study were purebred. There is no research identifying breed specificity, but pedigree breeds were affected in published OC studies $[6,16,21,22]$. The findings suggest that genetics play an important role in OC development. On the contrary, crossbred calves were affected in other studies, which negates the genetic theory $[3,18]$. In cattle OC, published studies recognized the condition in purebred, intact male [21,22]. Our study also showed a slight male predisposition. However, the cases were few and limited. In future, more cases need to be analyzed to judge the correlation between sex and OC in JB calves.

Histopathological findings observed in this study resembled lesions observed in a clinical case of shoulder OC [18] including inflammation and granulation tissue, which suggested tissue repair. Findings in other cattle OC showed similar findings except inflammation [20]. The reason speculated is these samples were obtained from slaughterhouse.

Treatment especially in cattle depends on severity of disease, value of animal and owner's requirement. Two owners declined treatment, probably based on the case prognosis. For the rest of the calves, arthrotomy was a preferred treatment in present study. Though Okada et al. [16] reported arthroscopic debridement for successful outcome in a JB calf, however, arthroscopy as a routine procedure remains difficult in cattle due to anatomical considerations [14] and economic constraints. In this study, arthrotomy had successful outcomes, which can be easily adapted in field conditions with the use of local analgesia and anesthesia commonly used in cattle.

Outcomes in this study were difficult to evaluate due to the small sample size, however those treated surgically were auctioned. Secondary degenerative joint disease had an impact on treatment outcomes in one old calf (nine-month-old). Three young calves (three to seven months old) with radiographic grade 1, grade 2 and grade 4 treated surgically were auctioned whereas one calf with grade 1 was sent for fattening. Authors suspect that the age of the calf (nine months), location of lesion, peri and post-operative management, bone maturation and delay in lameness improvement were the reasons the animal was not auctioned. On the other hand, Trostle et al. [21] reported that the co-existence of degenerative joint disease did not affect the treatment outcome. In addition, we, however, must note that we cannot evaluate the effectiveness of two treatments (surgery and conservative) because the severity of the cases which received surgery and cases which received conservative management were different.

Only one calf was treated conservatively using IA medication and stall rest and had a good outcome. Post IA injection, no complications were observed. However, septic arthritis following IA medication is reported in horses [7, 19]. This is a major reason cattle veterinarians are skeptical and in dilemma regarding IA injections. Steel et al. [19] identified veterinarian and type of corticosteroid as risk factors for septic arthritis and suspected lack of following strict aseptic protocol by some veterinarians. On the contrary, Gillespie et al. [7] reported that there was a low incidence of sepsis of joint if common injection methods were used. In addition, rapid progression of osteoarthritis, subchondral insufficiency fracture, osteonecrosis and bone loss were also reported as adverse conditions in human and enough evaluation must be made using diagnostic imaging before IA injection [9]. Another human study also reports that corticosteroid used for IA injections at high doses for an extended period of time can have adverse effects on cartilage [23]. Hence, surgery should be considered for unresolved chronic cases to avoid subsequent cartilage damage and progression to secondary osteoarthritis.

Survey radiographs can detect asymptomatic OC which is a routine practice in horses [10]. On the other hand, survey radiography is uncommon in cattle. In JB calves, bone maturation is a rapid process until five months of age and displays minimal changes after 10 months and was not affected by sex of the calf [15]. Even in this study, if periodic screening would have been performed, outcomes might have improved. In future, survey radiographs at regular interval should be considered until five months of age to detect early lesions of OC and prevent initiation of secondary degenerative joint disease.

In conclusion, radiography is sufficient to diagnose OC in JB cattle along with history and clinical signs in a clinical setting. Surgery should be considered even for small lesions for a successful outcome in JB calves. A modified radiographic grading criteria for clinical cases may hold potential in evaluating prognosis and outcomes.

\section{REFERENCES}

1. Baccarin, R. Y. A., Pereira, M. A., Roncati, N. V., Bergamaschi, R. R. C. and Hagen, S. C. F. 2012. Development of osteochondrosis in Lusitano foals: a radiographic study. Can. Vet. J. 53: 1079-1084. [Medline]

2. Craig, L. E., Dittmer, K. E. and Thompson, K. G. 2016. Bones and joints. pp. 16-163. In: Pathology of Domestic Animals, 6th ed. (Maxie, M. G. ed.), Elsevier, St. Louis.

3. Davies, I. H. and Munro, R. 1999. Osteochondrosis in bull beef cattle following lack of dietary mineral and vitamin supplementation. Vet. Rec. 145: 232-233. [Medline] [CrossRef]

4. Desrochers, A. 2013. Non-infectious lameness. WCDS Advances in Dairy Technology 25: 255-266.

5. Desrochers, A., Anderson, D. E. and St-Jean, G. 2001. Lameness examination in cattle. Vet. Clin. North Am. Food Anim. Pract. 17: 39-51, v-vi. [Medline] [CrossRef]

6. Emerson, S. E., Holt, T. N., Rao, S., Bass, L., Enns, R. M. and Barrett, M. F. 2018. Incidence and characteristics of juvenile tarsocrural osteochondrosis in purebred Angus bulls. Vet. J. 237: 34-36. [Medline] [CrossRef]

7. Gillespie, C. C., Adams, S. B. and Moore, G. E. 2016. Methods and variables associated with the risk of septic arthritis following intra-articular 
injections in horses: a survey of veterinarians. Vet. Surg. 45: 1071-1076. [Medline] [CrossRef]

8. Jensen, R., Park, R. D., Lauerman, L. H., Braddy, P. M., Horton, D. P., Flack, D. E., Cox, M. F., Einertson, N., Miller, G. K. and Rehfeld, C. E. 1981. Osteochondrosis in feedlot cattle. Vet. Pathol. 18: 529-535. [Medline] [CrossRef]

9. Kompel, A. J., Roemer, F. W., Murakami, A. M., Diaz, L. E., Crema, M. D. and Guermazi, A. 2019. Intra-articular corticosteroid injections in the hip and knee: perhaps not as safe as we thought? Radiology 293: 656-663. [Medline] [CrossRef]

10. McCoy, A. M., Toth, F., Dolvik, N. I., Ekman, S., Ellermann, J., Olstad, K., Ytrehus, B. and Carlson, C. S. 2013. Articular osteochondrosis: a comparison of naturally-occurring human and animal disease. Osteoarthritis Cartilage 21: 1638-1647. [Medline] [CrossRef]

11. Mez, J. C. 2015. Osteochondrosis. pp. 1085-1087. In: Large Animal Internal Medicine, 5th ed. (Smith, B. P. ed.), Elsevier, St. Louis.

12. Mulon, P. Y. 2009. Osteochondrosis in cattle. pp. 262-263. In: Current Veterinary Therapy Food Animal Practice, 5th ed. (Anderson, D. E. and Rings, D. M. eds.), Elsevier, St. Louis.

13. Mulon, P. Y., Babkine, M., d'Anjou, M. A., Girard, C. and Desrochers, A. 2009. Degenerative disease of the distal interphalangeal joint and sesamoid bone in calves: 9 cases (1995-2004). J. Am. Vet. Med. Assoc. 234: 794-799. [Medline] [CrossRef]

14. Nichols, S. and Lardé, H. 2014. Noninfectious joint disease in cattle. Vet. Clin. North Am. Food Anim. Pract. 30: 205-223, vii. [Medline] [CrossRef]

15. Oishi, A., Hamada, S., Sakamoto, H., Kamiya, S., Yanagida, K., Kubota, C., Watanabe, Y. and Shimizu, R. 1996. Radiographical evaluation of bone maturation in Japanese black beef cattle. J. Vet. Med. Sci. 58: 529-535. [Medline] [CrossRef]

16. Okada, R., Imai, N., Ando, T., Kohiruimaki, M., Ohtsuka, H., Watanabe, D. and Oikawa, M. 2008. Osteochondrosis with subchondral bone deficit in a Japanese black calf. Jpn. J. Vet. Clinics 31: 154-159 (in Japanese with English summary). [CrossRef]

17. Rohde, C., Anderson, D. E., Desrochers, A., St-Jean, G., Hull, B. L. and Rings, D. M. 2000. Synovial fluid analysis in cattle: a review of 130 cases. Vet. Surg. 29: 341-346. [Medline] [CrossRef]

18. Scott, P. R., Rhind, S. and Brownstein, D. 2000. Severe osteochondrosis in two 10-month-old beef calves. Vet. Rec. 147: 608-609. [Medline] [CrossRef]

19. Steel, C. M., Pannirselvam, R. R. and Anderson, G. A. 2013. Risk of septic arthritis after intra-articular medication: a study of 16,624 injections in Thoroughbred racehorses. Aust. Vet. J. 91: 268-273. [Medline] [CrossRef]

20. Taura, Y., Sasaki, N., Nishimura, R., Takeuchi, A. and Usui, K. 1996. Histopathological findings on ulcerative lesions of carpal and tarsal joints in Japanese black cattle. J. Vet. Med. Sci. 58: 135-139. [Medline] [CrossRef]

21. Trostle, S. S., Nicoll, R. G., Forrest, L. J. and Markel, M. D. 1997. Clinical and radiographic findings, treatment, and outcome in cattle with osteochondrosis: 29 cases (1986-1996). J. Am. Vet. Med. Assoc. 211: 1566-1570. [Medline]

22. Weisbrode, S. E., Monke, D. R., Dodaro, S. T. and Hull, B. L. 1982. Osteochondrosis, degenerative joint disease, and vertebral osteophytosis in middle-aged bulls. J. Am. Vet. Med. Assoc. 181: 700-705. [Medline]

23. Wernecke, C., Braun, H. J. and Dragoo, J. L. 2015. The effect of intra-articular corticosteroids on articular cartilage. Orthop. J. Sports Med. 3: 2325967115581163. [Medline] [CrossRef] 